\title{
Fit and Vigilant: The Relationship Between Poorer Aerobic Fitness and Failures in Sustained Attention During Preadolescence
}

\author{
Matthew B. Pontifex, Mark R. Scudder, Eric S. Drollette, and Charles H. Hillman \\ University of Illinois at Urbana-Champaign
}

\begin{abstract}
With the growing trend toward engagement in sedentary behaviors during childhood, a greater understanding of the relationship between cardiorespiratory fitness and cognition during development is of increasing importance. Objective: The aim of this investigation was to assess the extent to which failures in sustained attention may underlie deficits in cognition associated with poorer aerobic fitness. Method: A sample of 62 preadolescent children between the ages of 9 and 10 years were separated into higherand lower-fit groups according to their cardiorespiratory fitness. Results: Findings indicated that lower-fit children exhibited poorer overall response accuracy during a task requiring aspects of cognitive control relative to their higher-fit counterparts, with a disproportionately greater number of errors of omission, and longer, more frequent sequential errors of omission. Conclusions: These findings suggest that poorer vigilance may contribute to deficits in cognitive control associated with poorer aerobic fitness.
\end{abstract}

Keywords: cognition, development, cardiorespiratory fitness, vigilance decrement

Over the past several decades there has been a growing emphasis on elucidating the effect of fitness on brain health and cognition, particularly during maturation, given increasing societal trends for children to participate in sedentary activities (Department of Health and Human Services \& Department of Education, 2000). Findings from these investigations have indicated that poorer cardiorespiratory fitness may be adversely related to cognitive health and function with less aerobically fit children exhibiting reduced academic achievement-in the areas of reading and arithmetic - and overall lower functioning on a number of aspects of cognition relative to higher-fit children (i.e., perception, memory, and concentration; Castelli, Hillman, Buck, \& Erwin, 2007; Hillman, Castelli, \& Buck, 2005; but see Sibley \& Etnier, 2003 and Tomporowski, 2003 for review). However, these investigations assessing the influence of aerobic fitness on cognition have predominately focused on the ability to execute a correct response and thus have largely ignored the extent to which deficits in cognition associated with poorer cardiorespiratory fitness may relate to failures in sustained attention (i.e., the ability to maintain attentional focus to task relevant details over time; Parasuraman, 1979; Warm, Parasuraman, \& Matthews, 2008).

Matthew B. Pontifex, Mark R. Scudder, Eric S. Drollette, and Charles H. Hillman, Department of Kinesiology and Community Health, University of Illinois at Urbana-Champaign.

Support for our research and the preparation of this article was provided by a grant from the National Institute of Child Health and Human Development (NICHD) to Charles Hillman (RO1 HD055352) and a fellowship awarded to Matthew Pontifex through the NICHD Developmental Psychobiology and Neurobiology Training Grant at the University of Illinois (2 T32 HD007333).

Correspondence concerning this article should be addressed to Matthew B. Pontifex, Department of Kinesiology, 27P IM Sports Circle, Michigan State University, East Lansing, MI 48824-1049. E-mail: pontifex@ msu.edu
Traditional sustained attention (also referred to as "vigilance") tasks require participants to attend and respond to infrequent target stimuli amid high-probability nontarget stimuli over long periods of time. According to the resource theory, this maintenance of attentional focus requires substantial neural resources such that over a prolonged period of time, depletion of attentional stores manifests as failures in sustained attention (i.e., a lack of a response when an action is required, resulting in an error of omission; Helton \& Warm, 2008; Temple et al., 2000; Warm, Parasuraman, \& Matthews, 2008). Thus, these failures in sustained attention are thought to allow for the regeneration of neural resources until attention can be reengaged (Fisk \& Schneider, 1981). A primary limitation of traditional vigilance tasks however, is that they can only be utilized in participant populations that are conducive to sitting still for a long enough period of time for attentional stores to be depleted. Accordingly, these tasks can range from as short as 8 minutes (Nuechterlein, Parasuraman, \& Jiang, 1983; Temple et al., 2000) to over $40 \mathrm{~min}$ in duration (Warm, 1984) for attentional stores to sufficiently be depleted to observe failures in sustained attention.

Interestingly, previous investigations have suggested that these failures in sustained attention may be rooted in the informationprocessing demands of the task (Hitchcock, Dember, Warm, Maroney, \& See, 1999; Warm, Dember, \& Hancock, 1996). That is, previous research has observed a negative association between attentional vigilance and cognitive load, such that failures in sustained attention occur with greater frequency as the amount of cognitive control required is increased (Caggiano \& Parasuraman, 2004; Fisk \& Schneider, 1981; Parasuraman, 1979). The term cognitive control (also referred to as "executive control") describes an overarching set of higher-order cognitive operations, which are involved in the regulation of goal-directed interactions within the environment (Botvinick, Braver, Barch, Carter, \& Cohen, 2001; Meyer \& Keiras, 1997; Norman \& Shallice, 1986). Accordingly, these resource intensive cognitive operations act to exert top-down 
control during ongoing information processing, allowing for improved attentional maintenance of task demands and representations (Diamond, 2006; MacDonald, Cohen, Stenger, \& Carter, 2000). Therefore, consistent with a more theoretical perspective of attentional vigilance; any task that sufficiently depletes neural resources in the maintenance of attention should eventually manifest with a lack of a response when an action is required-thus indicating a failure in sustained attention (Helton \& Warm, 2008; Temple et al., 2000; Warm, Parasuraman, \& Matthews, 2008).

Given the apparent link between cognitive control and failures in sustained attention, the first purpose of this investigation was to determine the extent to which a classical cognitive control task, the Eriksen flanker task (Eriksen \& Eriksen, 1974), might be utilized as a short duration assessment of sustained attention. The Eriksen flanker task is a paradigm that has been extensively utilized in cognitive control research to tap aspects of inhibitory control, one aspect of cognitive control. Inhibition is believed to be particularly important for the effective functioning of other aspects of cognition (Barkley, 1997; Brocki \& Brohlin, 2004), given that it relates to the ability to override a prepotent response to perform a less potent but correct response, gate out task irrelevant information in the stimulus environment, and stop an ongoing response (Barkley, 1997; Davidson, Amso, Anderson, \& Diamond, 2006). It is these abilities that are thought to be vital to sustaining attention and maintaining control over one's actions (Diamond, 2006). Accordingly, the Eriksen flanker task may provide fertile ground to assess sustained attention, as the inhibitory demands of the task exert a substantial toll on available neural resources (Eriksen \& Eriksen, 1974) and may more quickly deplete attentional stores thus engendering failures in sustained attention. Further, given the relatively protracted development of inhibitory control, this task may be particularly useful for the assessment of attentional vigilance during preadolescent childhood as these processes are still largely inefficient (Blakemore \& Choudhury, 2006; Diamond, 2006; Luna, Garver, Urban, Lazar, \& Sweeney, 2004).

The second purpose of the present investigation was to determine how deficits in sustained attention might relate to deficits in cognitive control associated with lower levels of cardiorespiratory fitness. That is, poorer aerobic fitness has been previously found to be associated with decreased cognitive performance across a variety of tasks, with a selectively greater deficit for aspects of cognition with larger cognitive control demands (Hillman, Buck, Themanson, Pontifex, \& Castelli, 2009; Pontifex et al., 2011; but see Hillman, Erickson, \& Kramer, 2008 for review). In particular, findings from Hillman et al. (2009) and Pontifex et al. (2011) have demonstrated that lower-fit preadolescent children exhibit behavioral deficits in response accuracy, with no changes in reaction time (RT), in response to a modified flanker task relative to their higher-fit counterparts. Although the mechanisms underlying these fitness-related differences in cognition are still unknown, a growing body of research has begun to investigate cardiovascular fitness-related differences in brain structure and function during development. Specifically, findings from these cross-sectional investigations of aerobic fitness have observed that lower-fit children exhibit a reduced ability to allocate attentional resources, delays in information processes, and inefficient action monitoring (Hillman et al., 2009, 2005; Pontifex et al., 2011).

Accordingly, if inefficient neural resource utilization relates to more frequent failures in sustained attention; children with lower aerobic fitness should exhibit a greater number of errors of omission (indicative of failures in sustained attention) relative to higher-fit children. Further, given that failures in sustained attention are believed to allow for the regeneration of neural resources until attention can be reengaged (Fisk \& Schneider, 1981), the hypothesized sedentary behavior-related failures in sustained attention should also be associated with longer delays in the reengagement of attention as indexed by greater frequency of error of omission runs (i.e., two or more sequential errors of omission) and the mean distance of error runs (i.e., the number of sequential errors). Accordingly, it was hypothesized that children with lower aerobic fitness would exhibit more frequent and longer lapses in sustained attention.

\section{Method}

\section{Participants}

Demographic and fitness data for all participants are provided in Table 1. Sixty-two preadolescent children (between the ages of 9 and 11 years old) from the east-central Illinois region were recruited from the general community through the use of University list-serves and fliers to serve as participants. Participants were separated based on aerobic fitness into higher-fit or lower-fit groups depending on whether their $\mathrm{VO}_{2}$ max fell above the 70th percentile or below the 30th percentile according to normative data provided by Shvartz and Reibold (1990). All participants provided written assent and their legal guardians provided written informed consent in accordance with the Institutional Review Board of the University of Illinois at Urbana-Champaign. Before testing, legal guardians' completed a health history and demographics questionnaire, reported that their child was free of neurological diseases, attentional disorders (as indexed by scores below the 80th percentile on the ADHD Rating Scale IV; DuPaul, Power, Anastopoulos, \& Reid, 1998), or physical disabilities, and indicated normal or corrected to normal vision. Legal guardians, in collaboration with

Table 1

Mean (SD) Values for Participant Demographics and Fitness Data

\begin{tabular}{lcc}
\hline \multicolumn{1}{c}{ Measure } & Higher-fit & Lower-fit \\
\hline$N$ & 28 (11 females) & 34 (17 females) \\
Age (years) & $10.0 \pm 0.6$ & $10.1 \pm 0.6$ \\
Tanner stage & $1.7 \pm 0.5$ & $1.6 \pm 0.5$ \\
K-BIT composite (IQ) & $115.3 \pm 8.3$ & $113.6 \pm 15.1$ \\
Socioeconomic status (SES) & $2.6 \pm 0.6$ & $2.7 \pm 0.6$ \\
ADHD & $7.2 \pm 4.5$ & $6.9 \pm 4.6$ \\
VO $_{2}$ max (ml/kg/min)* & $52.8 \pm 4.6$ & $35.7 \pm 5.2$ \\
VO $_{2}$ max percentile* & $83.1 \pm 4.6$ & $8.9 \pm 5.3$ \\
Physical activity (hours) $^{*}$ & $6.3 \pm 7.6$ & $4.2 \pm 4.6$ \\
\hline
\end{tabular}

Note. $\mathrm{ADHD}=$ raw scores on the Attention Deficit Hyperactivity Disorder Rating Scale IV. SES was determined using a trichotomous index based on: (1) participation in free or reduced-price lunch program at school, (2) the highest level of education obtained by the mother and father, and (3) number of parents who worked full-time (Hillman et al., in press). $\mathrm{VO}_{2} \mathrm{max}$, maximum oxygen consumption. Normative values for $\mathrm{VO}_{2} \mathrm{max}$ may be found in Shvartz and Reibold (1990). Physical activity, total hours of self-reported physical activity per week.

${ }^{*} p \leq .05$. 
their child, completed the Tanner Staging Scales (Taylor et al., 2001), indicating that the participant's pubertal status was at or below a score of 2 (i.e., prepubescent) on a 5-point scale. Additionally, children were administered the Kaufman Brief Intelligence Test (K-BIT; Kaufman \& Kaufman, 1990) by a trained experimenter to assess IQ with all children falling above a score of 85 , which would indicate clinical impairment (Kaufman \& Kaufman, 1990).

\section{ADHD Rating Scale IV}

The ADHD Rating Scale IV is an 18 item inventory completed by the parent/legal guardian based upon the diagnostic criteria for attention deficit hyperactivity disorder (ADHD) as described in the fourth edition of the Diagnostic and Statistical Manual of Mental Disorders. The overall score is based upon the sum of the scores for each of the 18 items, normalized by age and sex based upon data from a sample of over 2,000 U.S. children. This inventory has been validated as a reliable instrument to assess ADHD symptoms in children and adolescents (Faries, Yalcin, Harder, \& Heiligenstein, 2001; Zhang, Faries, Vowles, \& Michelson, 2005).

\section{Tanner Staging Scales}

The Tanner Pubertal Timing Scales (Taylor et al., 2001) are a valid and reliable measure of pubertal status, which use self-ratings based upon schematic drawings of secondary sexual characteristics and have been found to correlate well with physical examinations based on Tanner stages (Morris \& Udry, 1980). In these self-rating assessments, participants and their legal guardian are presented with sex-appropriate schematic drawings and are asked to rate where the participant falls on the scale based on the drawings. Ratings across pictures yield a single score of pubertal status (ranging from 1, prepubertal to 5, adult).

\section{Kaufman Brief Intelligence Test}

The K-BIT is a motor-free, individually administered screening tool used to assess verbal and nonverbal intelligence in individuals across the life span (Kaufman \& Kaufman, 1990). This measure is comprised of expressive vocabulary and definition subtests, which make up a verbal intelligence score; a matrices section, which makes up the nonverbal intelligence score; and a composite scale comprised of the verbal and nonverbal intelligence scores. This test is widely used within this age group and has been found to be a valid and reliable instrument for rapidly assessing IQ, with independent validation observing a high correlation between the Verbal, Nonverbal, and Composite scales for the K-BIT and the Wechsler Adult Intelligence Scale-Revised (Naugle, Chelune, \& Tucker, 1993, but see Canivez, Neitzel, \& Martin, 2005 for review).

\section{Task}

A modified flanker task (Eriksen \& Eriksen, 1974; Pontifex et al., 2009, 2011) was used to assess inhibitory aspects of cognitive control. This paradigm is conceptually simplistic in that it requires the discrimination of a centrally presented target stimulus amid lateral flanking stimuli, with participants being instructed to make a left hand thumb press when the target stimulus pointed left and a right hand thumb press when the target stimulus pointed right. In this task, perceptually induced response interference can be evoked by manipulating the compatibility of the target and flanking stimuli. In the congruent array (e.g., $\lll$ or $\ggg)$, the target stimulus and the flanking stimuli are identical, resulting in faster and more accurate responses relative to the incongruent array (e.g., $\gg<\gg$ or $\ll>\ll)$, where the target and flanking stimuli are mapped to opposing action-schemas (Eriksen \& Schultz, 1979). Two blocks of 100 trials were presented with equiprobable congruency and directionality. The stimuli were $3 \mathrm{~cm}$ tall white arrows, which were presented focally for $200 \mathrm{~ms}$ on a black background with a response window of 100 to $1,650 \mathrm{~ms}$ after stimulus onset, and a fixed intertrial interval of $1,700 \mathrm{~ms}$. Errors of commission were defined as incorrect responses, while errors of omission were defined as a lack of a response during the response window. No responses were observed outside of the $1,650 \mathrm{~ms}$ response window (during the -50 to $100 \mathrm{~ms}$ window surrounding stimulus-onset).

\section{Cardiorespiratory Fitness Assessment}

Maximal oxygen consumption $\left(\mathrm{VO}_{2} \mathrm{max}\right)$ was measured using a computerized indirect calorimetry system (ParvoMedics True Max $2400)$ with averages for oxygen uptake $\left(\mathrm{VO}_{2}\right)$ and respiratory exchange ratio (RER; $\mathrm{VCO}_{2} / \mathrm{VO}_{2}$ ) assessed every $20 \mathrm{~s}$. A modified Balke protocol (American College of Sports Medicine [ACSM], 2006) was used using a motor-driven treadmill at a constant speed with $2.5 \%$ increases in grade every 2 min until volitional exhaustion. A Polar heart rate monitor (Polar WearLink+31, Polar Electro, Finland) was used to measure heart rate throughout the test, and ratings of perceived exertion (RPE) were assessed every 2 min using the children's OMNI scale (Utter et al., 2002). Relative peak oxygen consumption was expressed in $\mathrm{ml} / \mathrm{kg} / \mathrm{min}$ and was based upon maximal effort as evidenced by: (1) a plateau in oxygen consumption corresponding to an increase of less than $2 \mathrm{ml} / \mathrm{kg} / \mathrm{min}$ despite an increase in workload, (2) a peak heart rate $\geq 185 \mathrm{bpm}$ (ACSM, 2006) and a heart rate plateau (Freedson \& Goodman, 1993); 3) RER $\geq 1.0$ (Bar-Or, 1983); and/or 4) ratings on the children's OMNI scale of perceived exertion $\geq 8$ (Utter et al., 2002). All participants were able to complete the cardiorespiratory fitness assessment.

\section{Procedure}

On the first visit to the laboratory, participants completed an informed assent and the K-BIT (Kaufman \& Kaufman, 1990). Concurrently, participants' legal guardians completed an informed consent, health history, and demographics questionnaire, the ADHD Rating Scale IV (DuPaul, Power, Anastopoulos, \& Reid, 1998), a modified Tanner Staging System questionnaire, and the Physical Activity Readiness Questionnaire (Thomas, Reading, \& Shephard, 1992) to screen for previous health issues that might be exacerbated by exercise. Participants were then fitted with a Polar heart rate monitor (Polar WearLink+31) and had their height and weight measured using a stadiometer and a Tanita WB-300 Plus digital scale, respectively. Participants were then invited to participate in the second day of testing if their $\mathrm{VO}_{2}$ max fell above the 70th percentile or below the 30th percentile according to normative data provided by Shvartz and Reibold (1990). On the second 
visit, participants were seated in a sound attenuated room and provided task instructions, afforded the opportunity to ask questions, and provided with 40 practice trials before the initiation of testing.

\section{Statistical Analysis}

Task performance (RT, response accuracy) was assessed separately using a 2 (fitness: higher-fit, lower-fit) $\times 2$ (congruency: congruent, incongruent) multivariate repeated measures ANOVA. Separate analyses were conducted to assess for potential fitness differences in the distribution of commission and omission errors, the number of error runs (two or more sequential errors), and the mean distance (number of sequential errors) for commission and omission errors using multiple probability corrected MannWhitney tests with a family wise alpha level of $p=.05$. The Mann-Whitney tests were chosen to account for the non-Gaussian distribution of the error data (Motulsky, 1995). Estimates of effect size, partial $\eta_{\mathrm{p}}^{2}$, are provided for all main effects and interactions.

\section{Results}

Preliminary analyses were performed to test for potential differences between the first and second block of 200 trials on the modified flanker task. Findings revealed no significant main effects or interactions involving trial block, $F \mathrm{~s}(1,60) \leq 3.5, p \geq$ $.07, \eta_{\mathrm{p}}^{2} \leq 0.06$. Thus, all further analyses were collapsed across blocks. Analyses were also performed to test whether sex was related to any of the behavioral effects. Findings revealed no significant main effects or interactions, $F_{\mathrm{s}}(1,58) \leq 3.2, p \geq .07$, $\eta_{\mathrm{p}}^{2} \leq 0.05$, thus all further analyses were collapsed across both sexes.

\section{Reaction Time}

Analysis revealed a main effect of Congruency, with longer RT latency for incongruent $(582.0 \pm 15.8 \mathrm{~ms})$ relative to congruent $(515.7 \pm 13.2 \mathrm{~ms})$ trials, $F(1,60)=93.0, p<.001, \eta_{\mathrm{p}}^{2}=0.61$. No fitness main effects or interactions were observed for RT latency, $F_{\mathrm{S}}(1,60) \leq 2.2, p \geq .14, \eta_{\mathrm{p}}^{2} \leq 0.04$.

\section{Response Accuracy}

Analysis revealed main effects of Fitness, with poorer response accuracy observed for the lower-fit group relative to the higher-fit group, $F(1,60)=7.6, p=.008, \eta_{\mathrm{p}}^{2}=0.11$, and Congruency, with decreased response accuracy for the incongruent $(74.8 \pm 1.7 \%)$ relative to congruent $(84.9 \pm 1.6 \%)$ trials, $F(1,60)=61.5, p<$ $.001, \eta_{\mathrm{p}}^{2}=0.51$.

\section{Error Analysis}

Further examination of the observed fitness differences in response accuracy was conducted by decomposing the distribution of commission errors (incorrect responses) relative to omission errors (non-responses). Findings revealed that a larger number of errors of omission occurred for the lower-fit relative to the higherfit group, Mann-Whitney $\mathrm{U}=329.5, \mathrm{Z}=2.1, p=.025$ (see Figure 1), with no significant group effects observed for errors of commission (incorrect responses), Mann-Whitney $\mathrm{U}=373, \mathrm{Z}=$
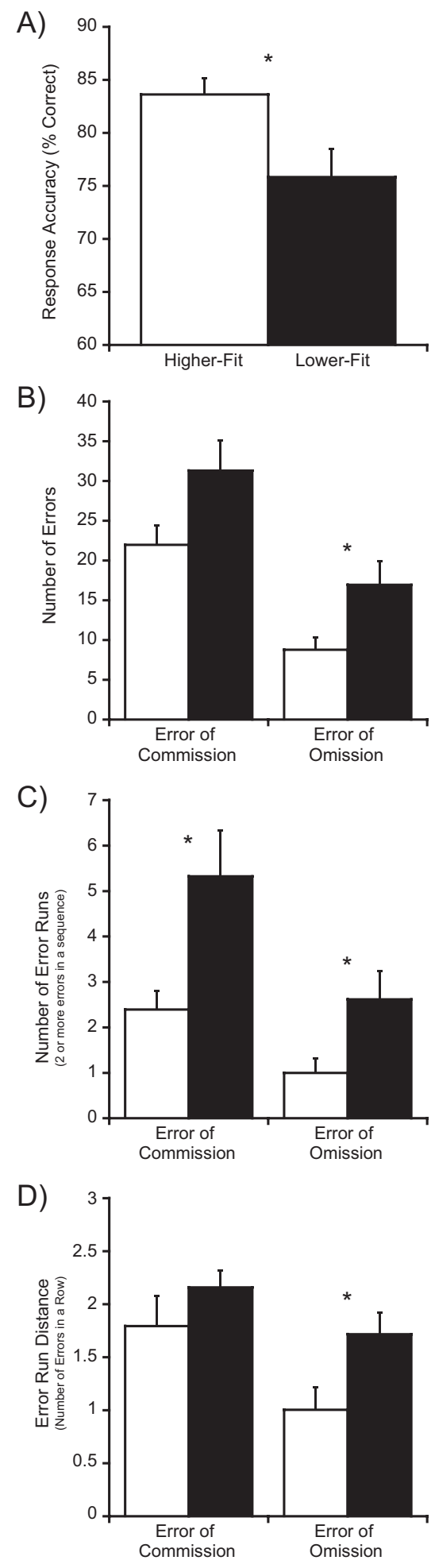

Figure 1. Mean (+1 SE) response accuracy (A); number of errors by error type (B); number of error runs (two or more errors in a sequence) by error type (C); and mean distance (number of sequential errors) by error type (D); based on cardiorespiratory fitness (white: higher-fit, black: lowerfit). 
$1.5, p=.15$. Further decomposition of the observed group differences in response accuracy was conducted by examining the number of error runs (two or more sequential errors) for omission and commission errors. Analysis revealed that the lower-fit, relative to the higher-fit, group exhibited more frequent error runs for both errors of omission, Mann-Whitney $\mathrm{U}=320.5, \mathrm{Z}=2.3, p=$ .02 , and errors of commission, Mann-Whitney $\mathrm{U}=293.5, \mathrm{Z}=$ 2.7, $p=.008$ (see Figure 1). Lastly, examination of the mean distance (number of sequential errors) revealed a larger number of sequential errors of omission for the lower-fit relative to the higher-fit group, Mann-Whitney $\mathrm{U}=324, \mathrm{Z}=2.3, p=.023$ (see Figure 1). No Fitness differences were observed for the number of sequential errors of commission, Mann-Whitney $\mathrm{U}=348.5, \mathrm{Z}=$ $1.8, p=.07$.

\section{Discussion}

In this investigation, we assessed the extent to which the flanker task might be utilized as a short duration assessment of sustained attention and the relation of these behavioral indices of sustained attention to deficits in cognitive control associated with lower aerobic fitness. The current findings suggest that the flanker task is effective in eliciting errors of omission, which are classically viewed as an index of failures in sustained attention. Further, these findings indicate that lower-fit children exhibited poorer overall response accuracy relative to their higher-fit counterparts, with a disproportionately greater number of errors of omission and longer, more frequent sequential errors of omission. Accordingly, these results provide initial evidence to suggest that failures of sustained attention may, in part, underlie fitness-related deficits in cognitive control.

Although the modified flanker task used within the present investigation is substantially different from traditional vigilance tasks (given that in essence every stimuli is a target stimuli rather than only being presented with infrequent targets), the heavy inhibitory control requirement to sustain attention and maintain control over ones actions during the completion of this task (Diamond, 2006) appears to be sufficient to engender vigilance failures in preadolescent children. Accordingly, these findings provide further support for the resource theory of sustained attention suggesting that failures of sustained attention result from mental fatigue and neural resource limitations (Davies \& Parasuraman, 1982; Helton et al., 2009; 2010; 2011; Temple et al., 2000; Warm et al., 2008). However, given the frequent responding and fastpaced nature of the flanker task, an alternative interpretation for the increased occurrence of errors of omission has been posited by Helton and colleagues (2011). That is, when responses are made frequently and rapidly, a ballistic feed-forward motor routine begins to develop resulting in modulations in response strategy rather than perceptual failures (Helton, Head, \& Russell, 2011; Helton, Kern, \& Walker, 2009; Helton, Weil, Middlemiss, \& Sawers, 2010). As participants begin to make errors when RT becomes too rapid, one means of motor inhibition is the complete cessation of motor actions resulting in an error of omission (Helton et al., 2011). Thus, such an interpretation questions the extent to which these short duration vigilance tasks assess vigilance or strategic disengagement (Helton et al., 2011, 2010, 2009).

If these errors of omission are indeed the result of tactical decisions to improve/maintain performance, rather than being indicative of failures of sustained attention, two important relationships should be observed. First, Helton and colleagues (2009) suggest that should this ballistic-feed forward motor routine modulate response strategy, it would be coupled with a correlation between RT and response accuracy such that as RTs become shorter, poorer response accuracy occurs. Within the present investigation, no statistically significant relationships were observed between mean RT and the number of errors of commission, the number of errors of omission, or overall response accuracy, $r s \leq .22, p s \geq 0.09$. The second indicator of motor inhibition underlying these errors of omission should be evidenced by shorter RT immediately before an error of omission relative to a correct response (Helton et al., 2011). However, within the present investigation, no statistically significant differences in RT were observed between mean RT, the RT for trials immediately preceding an error of omission, or the RT for trials immediately after an error of omission, $t \mathrm{~s}(61) \leq 1.4, p \mathrm{~s} \geq 0.16$. Given that in both instances, no relationship was observed, these findings suggest that cognitive control tasks_-such as the flanker task-may indeed provide a short duration means of probing attentional vigilance. However, one limitation of the present investigation that should be noted is that a more traditional vigilance task was not collected. Thus, further research is still necessary to better determine the extent to which errors of omission in traditional vigilance tasks and tasks such as the modified flanker assess similar aspects of sustained attention.

Relative to cardiorespiratory fitness, the current findings add to a growing body of literature suggesting that lower fitness is associated with deficits in task performance (Hillman et al., 2009, 2005) and deficient post-error adjustments in behavior (Themanson et al., 2008). Specifically, in the current investigation, lower-fit participants committed twice as many error of commission runs (two or more sequential errors) than their higher-fit counterparts. These findings replicate those reported by Themanson and colleagues (2008), who observed decreased post-commission error accuracy for lower-fit, relative to higher-fit, participants; such that subsequent post-commission error adjustments in cognitive control were insufficient to prevent a second sequential commission error (Rabbitt, 1966). Taken together, these findings suggest that lower cardiorespiratory fitness may be associated with deficient compensatory adjustments in cognitive control to initiate behavioral corrections after the commission of an error.

Novel to the present investigation was the assessment of behavioral indices of sustained attention with lower-fit children exhibiting more frequent failures in sustained attention, as indexed by an increased occurrence of errors of omission. Because failures in sustained attention occur as attentional resources diminish, these fleeting instances are thought to allow for the regeneration of neural resources until attention can be reengaged (Fisk \& Schneider, 1981). A behavioral index of the ability to regenerate neural resources can therefore be obtained by assessing the frequency of omission error runs (i.e., two or more sequential errors of omission) and the mean distance of omission error runs (i.e., the number of sequential errors of omission). Findings from the current investigation suggest that lower-fit children experience more frequent and longer delays in the regeneration and engagement of attention, exhibiting over twice as many error of omission runs and taking nearly twice the number of trials to reengage (as indexed by a greater number of consecutive errors of omission). Collectively, these findings suggest that lower cardiorespiratory fitness relates to an increased occurrence of failures in sustained attention during 
a cognitive control task, necessitating more frequent and longer time for the regeneration of neural resources.

The mechanisms underlying fitness-related deficits in sustained attention likely relate to differences in brain structure and function. That is, a growing body of research has observed that lower cardiorespiratory fitness during development is associated with decreased integrity of the neural networks underlying aspects of cognitive control (see Chaddock et al., 2011 for review). Specifically, findings from cross-sectional investigations of aerobic fitness in preadolescent children have observed modulations in neuroelectric indices of cognition, with lower aerobic fitness being associated with deficits in response inhibition as indexed by increased $\mathrm{N} 2$ amplitude, reductions in the allocation of attentional resources as indexed by smaller P3 amplitude, delays in the speed of information processing as indexed by longer P3 latency, and decreased integrity of action-monitoring processes as indexed by increased ERN amplitude (Hillman et al., 2009, 2005; Pontifex et al., 2011). Accordingly, poorer aerobic fitness may be associated with inefficient neural resource allocation resulting in more frequent and longer lapses of sustained attention. Beyond functional deficits in cognition associated with cardiorespiratory fitness, deficits in neural structures in the basal ganglia and hippocampus have also been observed in lower- compared to higher-fit children along with poorer performance on inhibitory control and relational memory tasks, respectively (Chaddock et al., 2010a, 2010b). It is important to note however, that the current investigation was cross-sectional in nature; thus future randomized controlled trials are necessary to determine whether these failures in sustained attention are the result of individual differences or group bias other than cardiorespiratory fitness, and how these failures relate to changes in brain structure and function.

\section{Conclusions}

Collectively, the findings reported herein replicate and extend previous research on children, which have observed deficits in higherorder cognitive function associated with poorer aerobic fitness, and provide initial evidence to suggest that these deficits may result from failures in sustained attention. Specifically, lower-fit children exhibited a disproportionately greater numbers of omission errors and longer, more frequent sequential runs of omission errors. These findings suggest that children with poorer-aerobic fitness experience more frequent failures in sustained attention during a cognitive control task, necessitating more frequent and longer time for the regeneration and engagement of attention. Accordingly, these data suggest that cardiorespiratory fitness may be an important modifiable lifestyle factor that has implications for the effective maturation of networks underlying attention and maximizing cognitive health and function during development.

\section{References}

American College of Sports Medicine. (2006). ACSM's guidelines for exercise testing and prescription (7th ed.). New York, NY: Lippincott Williams \& Wilkins.

Barkley, R. A. (1997). Behavioral inhibition, sustained attention, and executive functions. Psychological Bulletin, 121, 65-94. doi:10.1037/ 0033-2909.121.1.65

Bar-Or, O. (1983). Pediatric sports medicine for the practitioner: From physiologic principles to clinical applications. New York: SpringerVerlag.
Blakemore, S. J., \& Choudhury, S. (2006). Development of the adolescent brain: Implications for executive function and social cognition. Journal of Child Psychology and Psychiatry, 47, 296-312. doi:10.1111/j.14697610.2006.01611.x

Botvinick, M. M., Braver, T. S., Barch, D. M., Carter, C. S., \& Cohen, J. D. (2001). Conflict monitoring and cognitive control. Psychological Review, 108, 624-652. doi:10.1037/0033-295X.108.3.624

Brocki, K. C., \& Brohlin, G. (2004). Executive functions in children aged 6-13: A dimensional and developmental study. Developmental Neuropsychology, 26, 571-593. doi:10.1207/s15326942dn2602_3

Caggiano, D. M., \& Parasuraman, R. (2004). The role of memory representation in the vigilance decrement. Psychonomic Bulletin \& Review, 11, 932-937. doi:10.3758/BF03196724

Canivez, G. L., Neitzel, R., \& Martin, B. E. (2005). Construct Validity of the Kaufman brief intelligence test, Wechsler intelligence scale for children-third edition, and adjustment scales for children and adolescents. Journal of Psychoeducational Assessment, 23, 15-34. doi: 10.1177/073428290502300102

Castelli, D. M., Hillman, C. H., Buck, S. M., \& Erwin, H. E. (2007). Physical fitness and academic achievement in 3rd and 5th grade students. Journal of Sport \& Exercise Psychology, 29, 239-252.

Chaddock, L., Erickson, K. I., Prakash, R. S., Kim, J. S., Voss, M. W., VanPatter, M., ... Kramer, A. F. (2010a). A neuroimaging investigation of the association between aerobic fitness, hippocampal volume and memory performance in preadolescent children. Brain Research, 1358, 172-183. doi:10.1016/j.brainres.2010.08.049

Chaddock, L., Erickson, K. I., Prakash, R. S., VanPatter, M., Voss, M. W., Pontifex, M. B., ... Kramer, A. F. (2010b). Basal ganglia volume is associated aerobic fitness in preadolescent children. Developmental Neuroscience, 32, 249-256. doi:10.1159/000316648

Chaddock, L., Pontifex, M. B., Hillman, C. H., \& Kramer, A. F. (2011). A review of the relation of aerobic fitness and physical activity to brain structure and function in children. Journal of the International Neuropsychological Society, 17, 975-985. doi:10.1017/S1355617711000567

Davidson, M. C., Amso, D., Anderson, L. C., \& Diamond, A. (2006). Development of cognitive control and executive functions from 4 to 13 years: Evidence from manipulations of memory, inhibition, and task switching. Neuropsychologia, 44, 2037-2078. doi:10.1016/j.neuropsychologia.2006.02.006

Davies, D. R., \& Parasuraman, R. (1982). The psychology of vigilance. London: Academic Press.

Department of Health and Human Services [DHHS] and Department of Education [DOE]. (2000). Promoting better health for young people through physical activity and sports. A Report to the President from the Secretary of Health and Human Services and the Secretary of Education. Silver Spring, MD: Centers for Disease Control.

Diamond, A. (2006). The early development of executive functions. In E. Bialystok, \& F. I. M. Craik (Eds.), Lifespan cognition: Mechanisms of change (pp. 70-95). New York, NY: Oxford University Press. doi: 10.1093/acprof:oso/9780195169539.003.0006

DuPaul, G. J., Power, T. J., Anastopoulos, A. D., \& Reid, R. (1998). ADHD Rating Scale-IV: Checklists, norms, and clinical interpretation. New York, NY: The Guilford Press.

Eriksen, C. W., \& Eriksen, B. A. (1974). Effects of noise letters upon the identification of a target letter in a non-search task. Perception and Psychophysics, 16, 143-149. doi:10.3758/BF03203267

Eriksen, C. W., \& Schultz, D. W. (1979). Information processing in visual search: A continuous flow conception and experimental results. Perception and Psychophysics, 25, 249-263. doi:10.3758/BF03198804

Faries, D. G., Yalcin, I., Harder, D., \& Heiligenstein, J. H. (2001). Validation of the ADHD Rating Scale as a clinician administered and scored instrument. Journal of Attention Disorders, 5, 107-115. doi:10.1177/ 108705470100500204

Fisk, A., \& Schneider, W. (1981). Control and automatic processing during 
tasks requiring sustained attention: A new approach to vigilance. Human Factors, 23, 737-750.

Freedson, P. S., \& Goodman, T. L. (1993). Measurement of oxygen consumption. In T. W. Rowland (Ed.), Pediatric laboratory exercise testing: Clinical guidelines (pp. 91-113). Champaign, IL: Human Kinetics.

Helton, W. S., Head, J., \& Russell, P. N. (2011). Reliable- and unreliablewarning cues in the sustained attention to response task. Experimental Brain Research, 209, 401-407. doi:10.1007/s00221-011-2563-9

Helton, W. S., Kern, R. P., \& Walker, D. R. (2009). Conscious thought and the sustained attention to response task. Conscious and Cognition, 18, 600-607. doi:10.1016/j.concog.2009.06.002

Helton, W. S., \& Warm, J. S. (2008). Signal salience and the mindlessness theory of vigilance. Acta Psychologica, 129, 18-25. doi:10.1016/ j.actpsy.2008.04.002

Helton, W. S., Weil, L., Middlemiss, A., \& Sawers, A. (2010). Global interference and spatial uncertainty in the sustained attention to response task (SART). Conscious and Cognition, 19, 77-85. doi:10.1016/ j.concog.2010.01.006

Hillman, C. H., Buck, S. M., Themanson, J. R., Pontifex, M. B., \& Castelli, D. (2009). Aerobic fitness and cognitive development: Event-related brain potential and task performance indices of executive control in preadolescent children. Developmental Psychology, 45, 114-129. doi: $10.1037 / \mathrm{a} 0014437$

Hillman, C. H., Castelli, D. M., \& Buck, S. M. (2005). Aerobic fitness and neurocognitive function in healthy preadolescent children. Medicine and Science in Sports and Exercise, 37, 1967-1974. doi:10.1249/ 01.mss.0000176680.79702.ce

Hillman, C. H., Erickson, K. I., \& Kramer, A. F. (2008). Be smart, exercise your heart: Exercise effects on brain and cognition. Nature Reviews Neuroscience, 9, 58-65. doi:10.1038/nrn2298

Hillman, C. H., Pontifex, M. B., Motl., R. W., O’Leary, K. C., Johnson, C. R., Scudder, M. R., . . Castelli, D. M. (2012). From ERPs to academics. Developmental Cognitive Neuroscience, 2S, S90-S98.

Hitchcock, E. M., Dember, W. N., Warm, J. S., Maroney, B. W., \& See, J. (1999). Effects of cueing and knowledge of results on workload and boredom in sustained attention. Human Factors, 41, 365-372. doi: 10.1518/001872099779610987

Kaufman, A. S., \& Kaufman, N. L. (1990). Kaufman Brief Intelligence Test manual. Circle Pines, MN: American Guidance Service.

Luna, B., Garver, K. E., Urban, T. A., Lazar, N. A., \& Sweeney, J. A. (2004). Maturation of cognitive processes from late childhood to adulthood. Child Development, 75, 1357-1372. doi:10.1111/j.14678624.2004.00745.x

MacDonald, A. W., III, Cohen, J. D., Stenger, V. A., \& Carter, C. S. (2000). Dissociating the role of the dorsolateral prefrontal and anterior cingulate cortex in cognitive control. Science, 288, 1835-1838. doi: 10.1126/science.288.5472.1835

Meyer, D. E., \& Kieras, D. E. (1997). A computational theory of executive cognitive processes and multi-task performance: Part 1. Basic mechanisms. Psychological Review, 104, 3-65. doi:10.1037/0033295X.104.1.3

Morris, N. M., \& Udry, J. R. (1980). Validation of a self-administered instrument to assess stage of adolescent development. Journal of Youth and Adolescence, 9, 271-280. doi:10.1007/BF02088471

Motulsky, H. (1995). Intuitive biostatistics. New York, NY: Oxford University Press.

Naugle, R. I., Chelune, G. J., \& Tucker, G. D. (1993). Validity of the Kaufman brief intelligence test. Psychological Assessment, 5, 182-186. doi:10.1037/1040-3590.5.2.182

Norman, D. A., \& Shallice, T. (1986). Attention to action: Willed and automatic control of behavior. In R. J. Davidson, G. E. Schwartz, \& D. Shapiro (Eds.), Consciousness and self-regulation: Vol. 4 Advances in research and theory (pp. 1-18). New York, NY: Plenum Press.

Nuechterlein, K. H., Parasuraman, R., \& Jiang, Q. (1983). Visual sustained attention: Image degradation produces rapid sensitivity decrement over time. Science, 220, 327-329. doi:10.1126/science.6836276

Parasuraman, R., Warm, J. S., \& See, J. E. (1998). Brain systems of vigilance. In R. Parasuraman (Ed.), The attentive brain (pp. 221-256). Cambridge, MA: The MIT Press.

Parasuraman, R. (1979). Memory load and event rate control sensitivity decrements in sustained attention. Science, 205, 924-927. doi:10.1126/ science. 472714

Pontifex, M. B., O’Connor, P., Broglio, S. P., \& Hillman, C. H. (2009). The Association between mild traumatic brain injury history and cognitive control. Neuropsychologia, 47, 3210-3216. doi:10.1016/j.neuropsychologia.2009.07.021

Pontifex, M. B., Raine, L. B., Johnson, C. R., Chaddock, L., Voss, M. W., Cohen, N. J., ... Hillman, C. H. (2011). Cardiorespiratory fitness and the flexible modulation of cognitive control in preadolescent children. Journal of Cognitive Neuroscience, 23, 1332-1345. doi:10.1162/ jocn.2010.21528

Rabbitt, P. M. A. (1966). Errors and error correction in choice-response tasks. Journal of Experimental Psychology, 71, 264-272. doi:10.1037/ h0022853

Shvartz, E., \& Reibold, R. C. (1990). Aerobic fitness norms for males and females aged 6 to 75 years: A review. Aviation, Space, and Environmental Medicine, 61, 3-11.

Sibley, B. A., \& Etnier, J. L. (2003). The relationship between physical activity and cognition in children: A meta-analysis. Pediatric Exercise Science, 15, 243-256.

Taylor, S. J. C., Whincup, P. H., Hindmarsh, P. C., Lampe, F., Odoki, K., \& Cook, D. G. (2001). Performance of a new pubertal self-assessment questionnaire: A preliminary study. Pediatric and Perinatal Epidemiology, 15, 88-94. doi:10.1046/j.1365-3016.2001.00317.x

Temple, J. G., Warm, J. S., Dember, W. N., Jones, K. S., LaGrange, C. M., \& Matthews, G. (2000). The effects of signal salience and caffeine on performance, workload, and stress in an abbreviated vigilance task. Human Factors, 42, 183-194. doi:10.1518/001872000779656480

Themanson, J. R., Pontifex, M. B., \& Hillman, C. H. (2008). Fitness and action monitoring: Evidence for improved cognitive flexibility in young adults. Neuroscience, 157, 319-328. doi:10.1016/j.neuroscience.2008.09.014

Thomas, S., Reading, J., \& Shephard, R. J. (1992). Revision of the Physical Activity Readiness Questionnaire (PAR-Q). Canadian Journal of Sport Sciences, 17, 338-345.

Tomporowski, P. D. (2003). Cognitive and behavioral responses to acute exercise in youths: A Review. Pediatric Exercise Science, 15, 348-359.

Utter, A. C., Roberson, R. J., Nieman, D. C., \& Kang, J. (2002). Children's OMNI scale of perceived exertion: Walking/running evaluation. Medicine \& Science in Sports \& Exercise, 34, 139-144. doi:10.1097/ 00005768-200201000-00021

Warm, J. S., Dember, W. N., \& Hancock, P. A. (1996). Vigilance and workload in automated systems. In R. Parasuraman \& M. Mouloua (Eds.), Automation and human performance: Theory and applications (pp. 183-200). Mahwah, NJ: Prentice Hall.

Warm, J. S., Parasuraman, R., \& Matthews, G. (2008). Vigilance requires hard mental work and is stressful. Human Factors, 50, 433-441. doi: $10.1518 / 001872008 X 312152$

Warm, J. S. (1984). An introduction to vigilance. In J. S. Warm (Ed.), Sustained attention in human performance (pp. 1-14). Chichester, UK Wiley.

Zhang, S., Faries, D. E., Vowles, M., \& Michelson, D. (2005). ADHD rating scale IV: Psychometric properties from a multinational study as a clinician-administered instrument. International Journal of Methods in Psychiatric Research, 14, 186-201. doi:10.1002/mpr.7

Received July 26, 2011

Revision received April 10, 2012 Accepted April 30, 2012 